\title{
Parallel symmetrical notches loaded patch antenna for wireless applications
}

\author{
Rakesh Kumar Bajpai ${ }^{1} \cdot$ Rajeev Paulus ${ }^{1} \cdot$ Ashish Singh $^{2} \cdot$ Mohammad Aneesh $^{3}$
}

(C) Springer Nature Switzerland AG 2019

\begin{abstract}
The theoretical analysis of parallel symmetrical notches loaded patch antenna for wireless applications is presented. The geometric analysis of the antenna is done to get the optimum results for wireless body area network. An antenna characteristic has been discussed for symmetrical notches length and width and distance between notches those optimum results. It is found that proposed antenna resonate at $2.37 \mathrm{GHz}$ having the bandwidth of $14 \mathrm{MHz}$. The results of parallel notches loaded patch antenna is compared with reported, theoretical, and measured results.
\end{abstract}

Keywords Notches · Symmetrical · Split ring resonator (SRR) $\cdot$ Wireless body area network (WBAN)

\section{Introduction}

With extensive increase in various wireless electronic gadgets for wireless application, especially in patient care monitoring through wireless gadgets has been used in our present day life. These wireless electronic gadgets are wearable and strong, light weight, cost effective, bio-compatible, and mechanically robust and low power device with satisfactory outputs. Therefore, WBAN are more suitable in medical field for wireless electronic equipment because such type of devices uses special type of antenna to communicate with nearby device or to transmit the information. In particular, WBAN are equipped with various types of patch antenna such as slot antenna, circular ring, inverted F-shaped antenna, grid array antenna, and filters etc. [1-9]

The patch antennas reported for WBAN applications such as shorting pin loaded circular patch antenna operating at $2.45 \mathrm{GHz}$, antenna designed with Y-shaped microstrip acting as ground plane, $6.8 \mathrm{dBi}$ gain switchable mode antenna, T-shaped design on FR4 with metal back ground, slot loaded rectangular patch with ground plane, dipole antenna with slots on ground plane, inverted F-shaped patch antenna with tapered feed to increased bandwidth, rectangular ring shaped as radiating top and $\mathrm{H}$-shaped slot on ground plane [1-4, 10-17]. All above discussed research papers of MSA are for WBAN but these papers has limitations such as complicated geometry, limited antenna gain and efficiency, parametric analysis is not provided and comparison with similar structure of antennas are not presented.

In this view, an antenna is proposed for wireless applications which have parallel symmetrical notches. The antenna performance has been studied theoretical and simulated results, further results are compared with similar radiating structures. All the antenna characteristics have been analyzed for wireless communication. The details of antenna design structures, radiation gain and efficiency are discussed in next section.

Ashish Singh, ashsin9@gmail.com; Rakesh Kumar Bajpai, rbajpai13@gmail.com; Rajeev Paulus, rajeev.paulus@shiats.edu.in | ${ }^{1}$ Department of Electronics and Communication, Sam Higginbottom Institute of Agriculture, Technology and Sciences, Allahabad 211007, India. ${ }^{2}$ Department of Electronics and Communication, NMAM Institute of Technology, Nitte, Udupi 574110 , India. ${ }^{3}$ Department of Electronics and Communication, Veer Bahadur Singh Purvancal University, Jaunpur 222003, India. 


\section{Antenna design and circuit analysis}

The antenna consist four notches that are so placed on the patch that represents like U-shaped from both side of the length of the patch. The patch is surrounded with rectangular path as shown in Fig. 1. Antenna design structure comprise of two parallel slots on bottom and top length. The proposed antenna is excited via SMA connector at point $(6.85,0)$ for both antennas with and without SRR. The radiating structure is designed over polyimide film (PF) have height $h=0.15 \mathrm{~mm}$ and dielectric constant $\epsilon_{r}$ 2.7. Figure 2 shows that current density on the proposed antenna, near the notches density of current is more and surround ring resonator it is less. This happens because of electromagnetic coupling between feed patch and square resonator.

Width of the rectangular patch is given as, $W_{1}=\frac{c}{2 f \sqrt{\frac{\epsilon_{r}+1}{2}}} \mathrm{~mm}$,

Length of the rectangular patch is given as, $L_{1}=\frac{c}{2 f \sqrt{\epsilon_{e}}} \mathrm{~mm}$,

$f=2.37 \mathrm{GHz}$ is the resonating frequency for proposed antenna; $c$ is the velocity of light in $\mathrm{mm} / \mathrm{s}$.

$\epsilon_{e}=$ effective dielectric constant.

The designed radiating structure can be represented into circuit system as shown in Fig. 3. A radiating structure
Fig. 1 Radiating geometry of designed antenna. Dimension in $\mathrm{mm} L=36, d=18.55$, $d_{1}=12.15, L_{3}=1.05, L_{p}=33.6$, $L_{n}=0.5, W=21, \mathrm{~W}_{\mathrm{n}}=2.7$, $W_{1}=8.1, W_{2}=13.3, W_{p 1}=1.2$, $W p=18.6, h=0.15 \mathrm{~mm}$, and permittivity $=2.7$
Fig. 2 Current distribution of electromagnetic coupled patch antenna
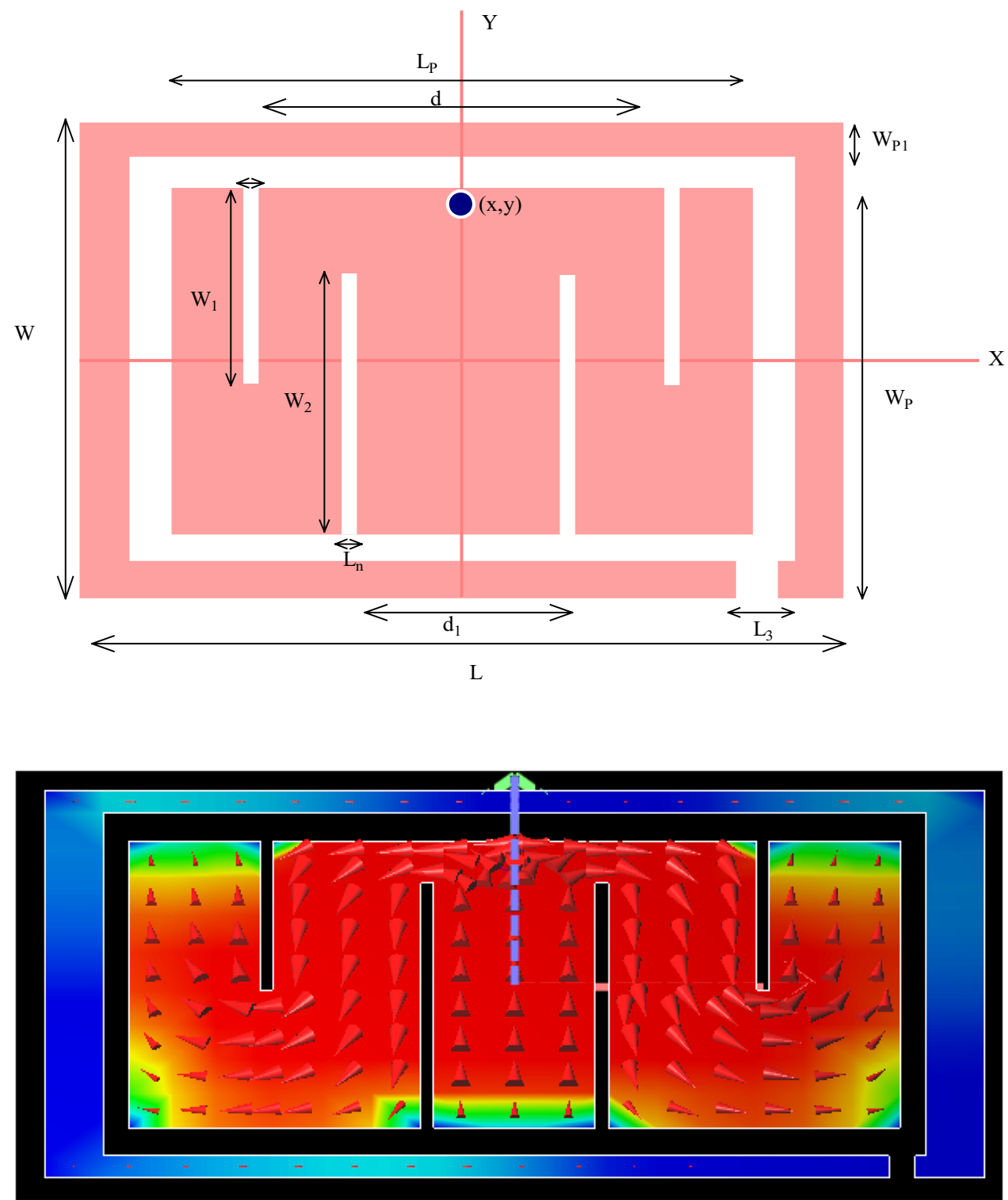


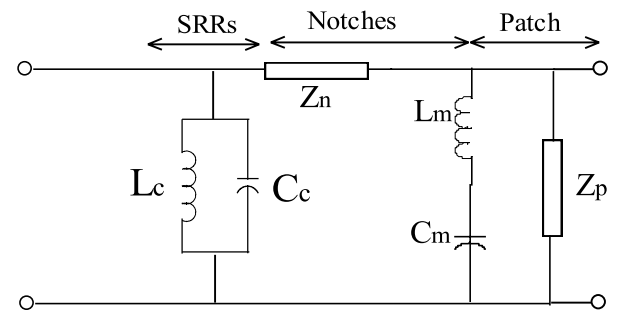

Fig. 3 Equivalent circuit of proposed antenna

consists of SRR which is represented as parallel combination of inductance $L_{c}$ and capacitance $C_{c}$ [18],

where $L_{L}=0.002 L\left(2.303 \log _{10}\left(\frac{4 L}{W}\right)-\gamma\right), \mu \mathrm{H}$

$\gamma=2.853$, constant of microstrip square loop,

$L=8 \Delta L-g, \mathrm{~mm}$

$\Delta L=$ externsion in length,$\quad g=$ gap between two arms,

$C_{c}=\frac{\in_{0} W W_{p 1}}{L_{3}}, \mathrm{pF}$

The resonating frequency $f_{S R R}$ of square microstrip loop is given as,

$f_{S R R}=\frac{1}{2 \pi} \sqrt{\frac{1}{L_{L} C_{C}}}, G H z$

The input impedance of rectangular patch is represented as $Z_{p}[19,20]$, which is the parallel combination inductance, capacitance, and inductance are given as,

$C_{p 1}=\frac{L_{1} W_{1} \varepsilon_{0} \varepsilon_{e}}{2 h} \cos ^{2}\left(\pi Y_{0} / L\right), \mathrm{pF}$

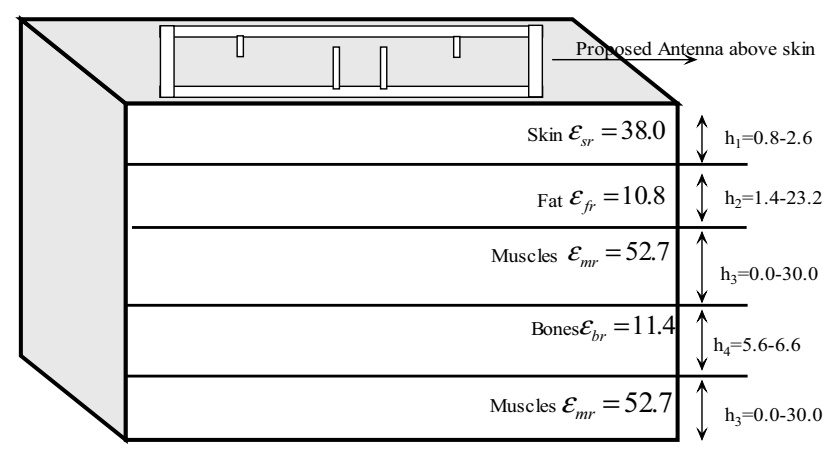

(a)
$R_{p 1}=Q / \omega_{r}^{2} C p_{1}$, ohms

$L_{p 1}=1 / \omega_{r}^{2} C_{p 1}, \mathrm{nH}$,

Resonating frequency of the rectangular patch is given as,

$f_{r}=\frac{c}{2 \pi \cdot L_{p 1} \sqrt{\varepsilon}_{e}}, \mathrm{GHz}$

The four notches have been represented as $Z_{n}$ with mutual inductance $L_{m}$ and capacitance $C_{m}[19]$, where $L_{m}$ and $C_{m}$ are given as,

$L_{m}=\frac{k_{c}^{2}\left(L_{p 1}+L_{2}\right)+\left[k_{c}^{4}\left(L_{p 1}+L_{2}\right)^{2}+4 k_{c}^{4}\left(1-k_{c}^{2}\right) L_{p 1} L_{2}\right]^{1 / 2}}{2\left(1-k_{c}^{2}\right)}$,

$C_{m}=\frac{-\left(C_{2}+C_{p 1}\right)+\left[\left(C_{2}+C_{p 1}\right)^{2}+\left(1-1 / k_{c}^{2}\right) C_{p 1} C_{2}\right]^{1 / 2}}{2}$,

$C_{2}=$ series combination of capacitances

$L_{2}=$ series combination of inductance.

The total input impedance of the proposed antenna is given as

$Z_{\text {in }}=\frac{1}{Z_{p}}+\frac{1}{Z_{m}}+Z_{n}+\frac{1}{Z_{c}}$

where $Z_{m}=j \omega L_{m}+\frac{1}{j \omega C_{m}}$ and $Z_{s r r}=\frac{1}{j \omega L_{c}}+j \omega C_{c}$.

\subsection{On body model without and with tumor}

The designed antenna is also simulated by considering the human body with and without tumor. Antenna is kept above the human body spacing between skin and antenna in $1 \mathrm{~mm}$ and an antenna is excited. Figure 4 the block diagram of on body human model with proposed antenna.

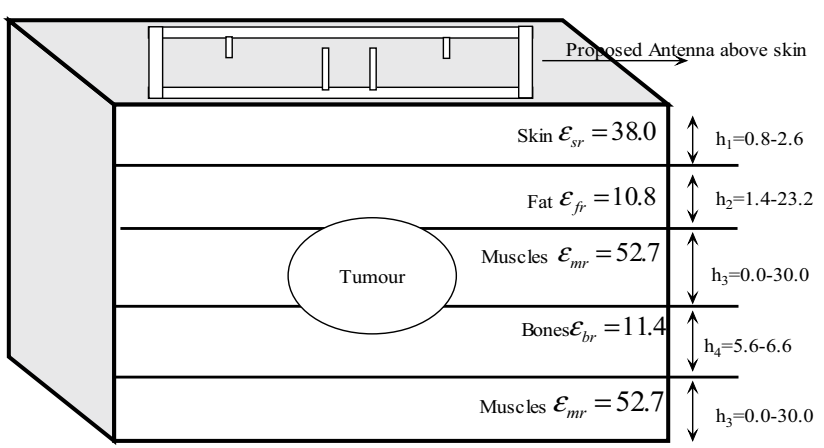

(b)

Fig. 4 Design of prototyped model of body considering $\mathbf{a}$ without and $\mathbf{b}$ with tumor/stone/swelling in muscles/fractured bone 


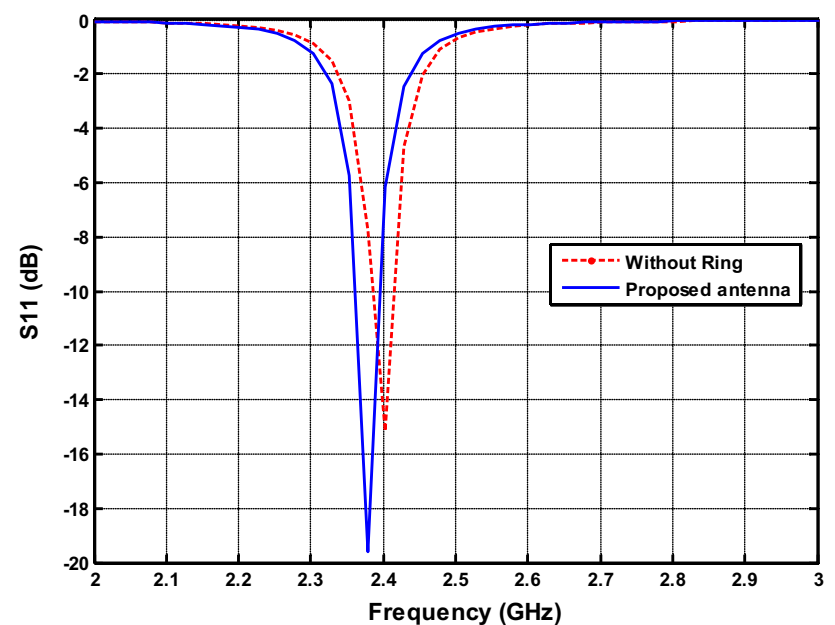

Fig. 5 Comparison of $S_{11}(d B)$ with frequency for the described antenna and without SRRs

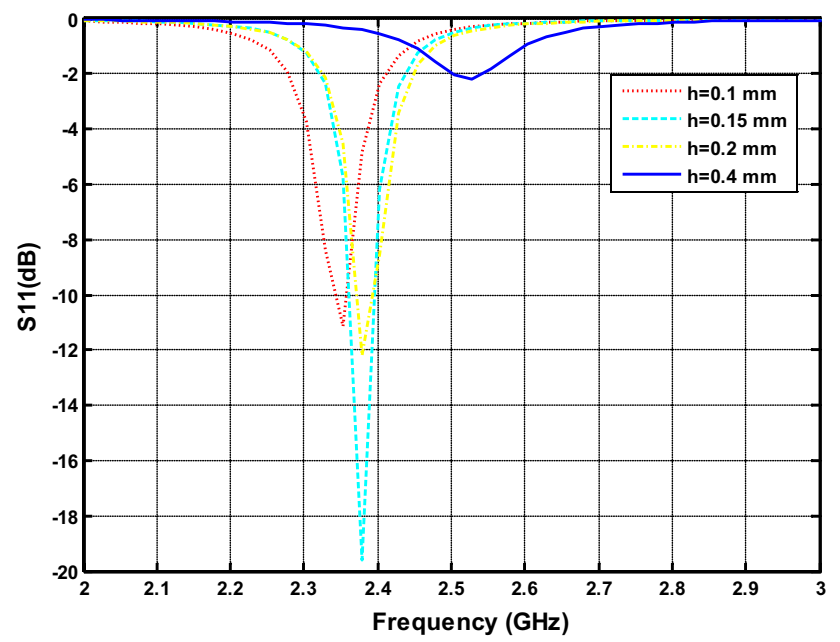

Fig. 6 The frequency versus $S_{11}(d B)$ for heights of substrate (h)

\section{Results and discussion}

The proposed antennas radiating structure are compared with plot shown in Fig. 5. It is observed that antenna resonate between 2.36 and $2.39 \mathrm{GHz}$ frequency which can be utilized for wireless application for WBAN and WMAN.

The height of proposed antenna $(h=0.15 \mathrm{~mm}$ for polymide film) is varied as shown in Fig. 6 . Firstly, it has been increased from $0.15 \mathrm{~mm}$ to $0.4 \mathrm{~mm}$ and changes are observed in resonating frequencies. It is found that at $h=0.4 \mathrm{~mm}$ antenna $\mathrm{S}_{11}$ is near $-2 \mathrm{~dB}$ means antenna is not radiating. At $h=0.1 \mathrm{~mm}$, the resonating frequency shift towards lower side with decrease in bandwidth and $\mathrm{S}_{11}$ is observed at $-11 \mathrm{~dB}$.

\section{SN Applied Sciences}

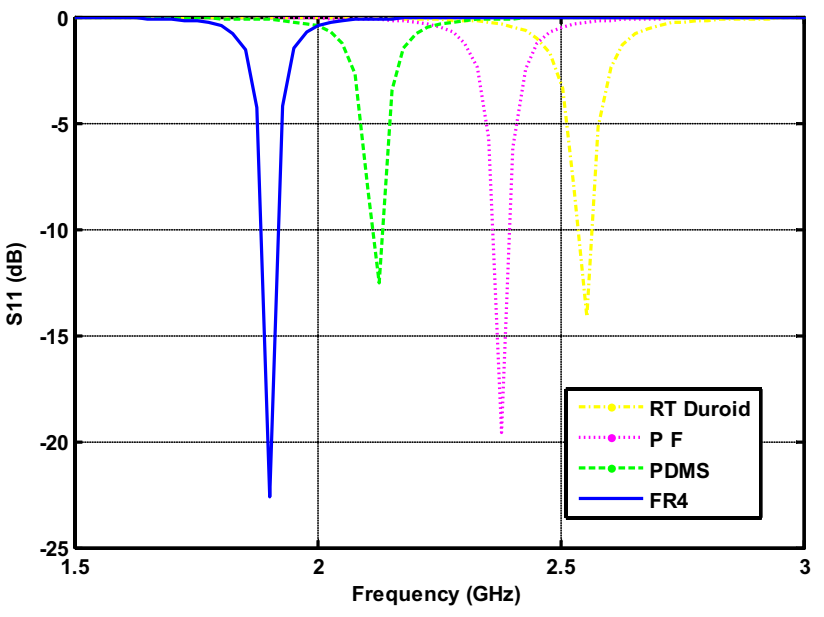

Fig. 7 The frequency versus $S_{11}(d B)$ on varying the dielectric of the antenna

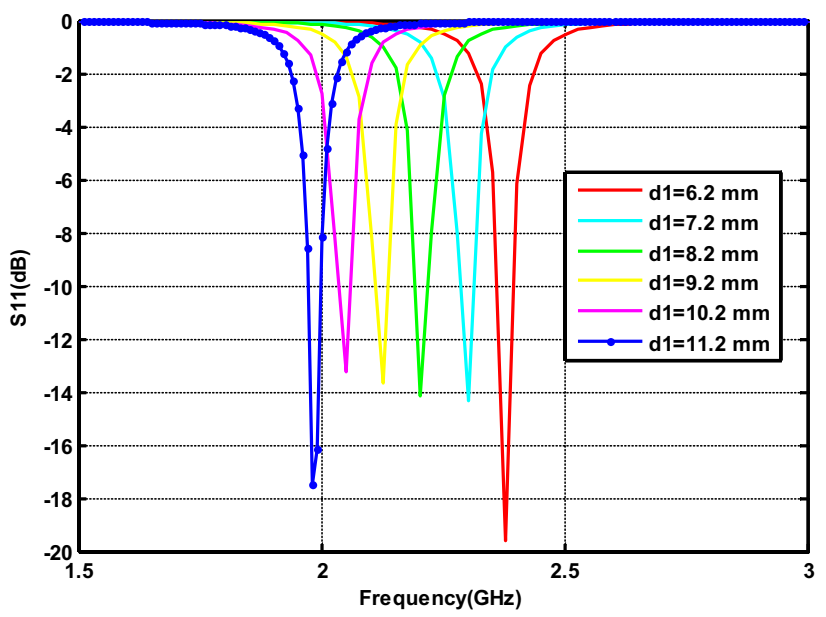

Fig. 8 The frequency versus $S_{11}(d B)$ for distance between the notches $d_{1}$

The permittivities of proposed antenna are varied and remaining other parameters is kept constant to examine the behavior of the permittivity on the antenna reflection coefficients as shown in Fig. 7. On decreasing permittivity of proposed antenna from 2.7 (PF) to 2.32 (RT Duroid) resonating frequency shifts from 2.37 to $2.52 \mathrm{GHz}$ whereas for the permittivity of PDMS it is noted that antenna resonates at $2.2 \mathrm{GHz}$ and for FR4 it is resonating at $1.9 \mathrm{GHz}$. This change in characteristics of the antenna is because of dielectric behavior of the material used.

Distance between the notches $d_{1}$ has been changed and noted the changes in reflection coefficient $S_{11}(\mathrm{~dB})$ as shown in Fig. 8. It is observed that distance between the notches $d_{1}$ has been changed from $d_{1}=8.2 \mathrm{~mm}$ to $6.2 \mathrm{~mm}$ 
then frequency band shifts from 2.37 to $2.47 \mathrm{GHz}$, whereas when $d_{1}$ is changed from 8.2 to $10.2 \mathrm{~mm}$ shifting in resonating frequency are observed from 2.37 to $1.99 \mathrm{GHz}$ and change in bandwidth is observed too.

Distance between the notches $d$ as per Fig. 1 and noted the changes in reflection coefficient $S_{11}(d B)$ as shown in Fig. 9. It is observed that on varying distance between the notches $d$ has been changed from $d=12.56$ to $18.56 \mathrm{~mm}$ then frequency band shift towards lower frequency side with decrease in bandwidth. It is found that at $d=17.56 \mathrm{~mm}$ and $18.56 \mathrm{~mm}$ resonating frequency has gone above $-10 \mathrm{~dB}$. The change in resonating frequency is observed because the change in electric current on the radiating surface.

The comparison plot is shown in Fig. 10 for the proposed radiating structure with and without cancer cells on human body. It is found that resonating frequency shifts as antenna is exposed to any opaque material depending upon the dielectric properties of the material. Similarly, when the proposed antenna is excited above the human body it has been observed that resonating frequency shifts from -19 to $-16 \mathrm{~dB}$ with decrease in bandwidth. Further, on considering the cancer cells the bandwidth decreases and it is observed that antenna is resonating at $2.37 \mathrm{GHz}$ near $-13.98 \mathrm{~dB}$. The proposed antenna is compared without SRRs also and it is found that resonating frequency is shifted from 2.37 to $2.41 \mathrm{GHz}$.

It is observed from the plot shown in Fig. 11 that simulated parallel notches loaded antenna structure has given similar results as in reported [21], simulated and theoretical results. It is found that there is no change in bandwidth of simulated and measured results but there change in the resonating length of frequency.

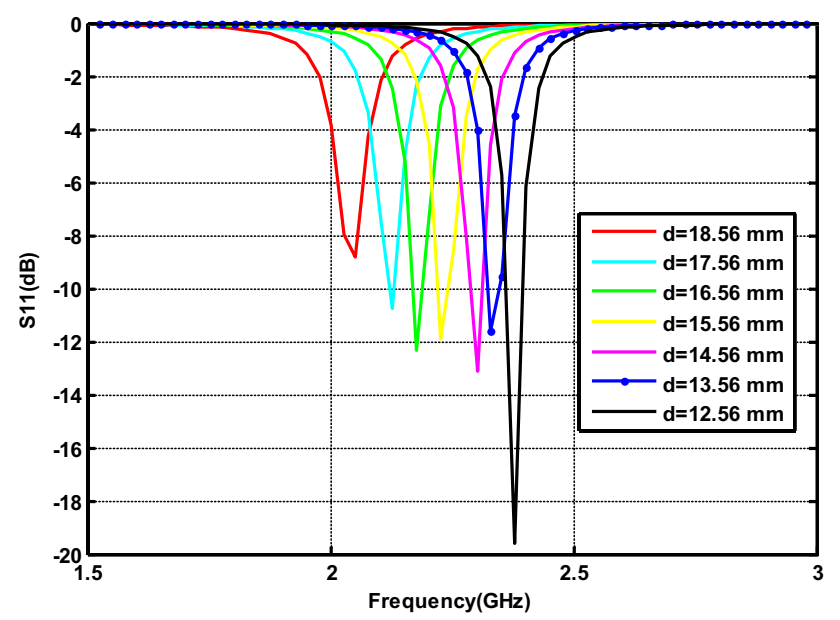

Fig. 9 The frequency versus $S_{11}(d B)$ for distance between the notches $d$

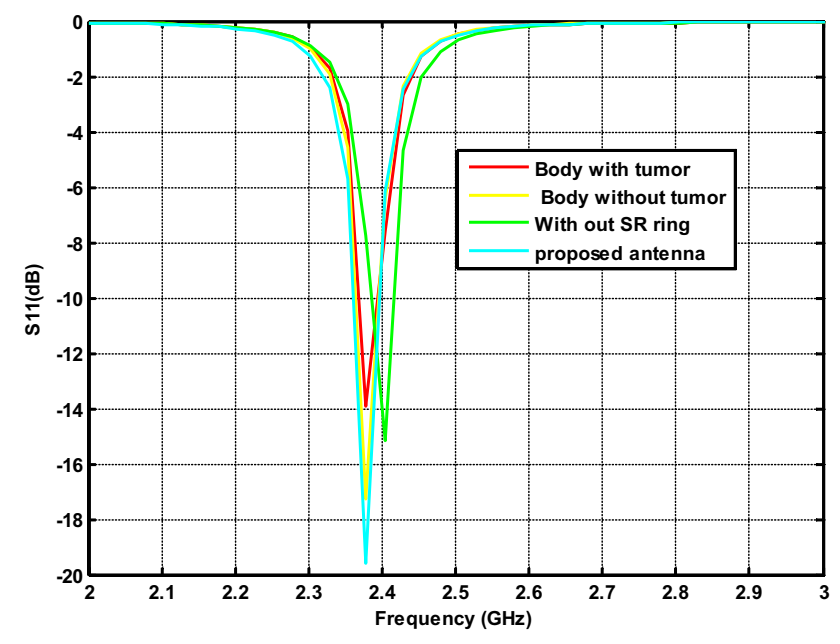

Fig. 10 The frequency versus $S_{11}(d B)$ for proposed radiating structure on human body model, with cancer cells, and splitted resonator rings

It is observed from the Fig. 12 that proposed antenna E-plane pattern has linear polarization in broadside direction with two beams like structure. This type of pattern is suitable for sensing the reflected signal from tumor, swelling, stones, fracture bones etc. Further, $\mathrm{H}$-plane pattern has $84.5^{\circ} 3-\mathrm{dB}$ beam width in broadside direction. The maximum gain of antenna is found to be $1.23 \mathrm{dBi}$ and $1.51 \mathrm{dBi}$ for simulation and theoretical examination.

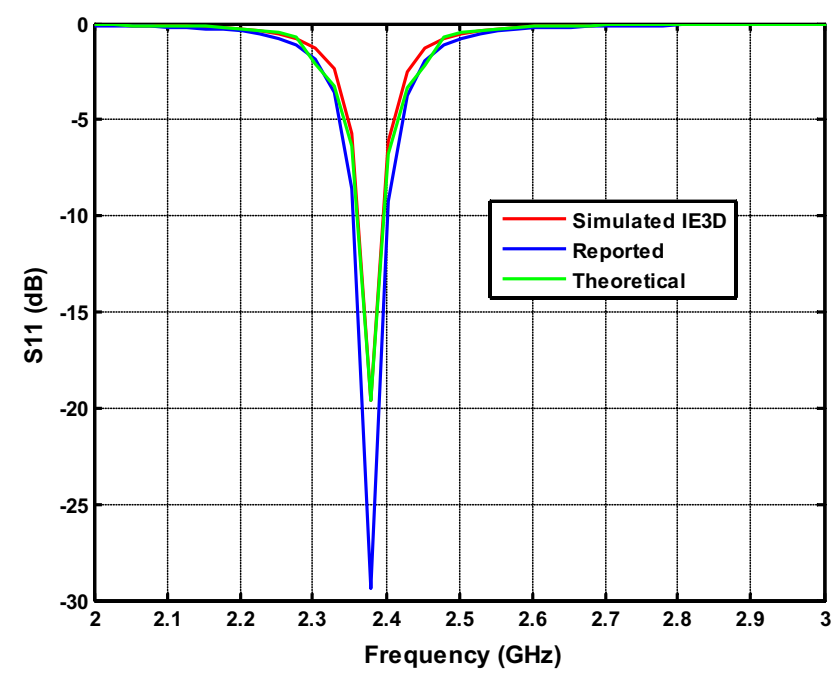

Fig. 11 The frequency versus $S_{11}(d B)$ for the reported [21], theoretical and proposed antenna 


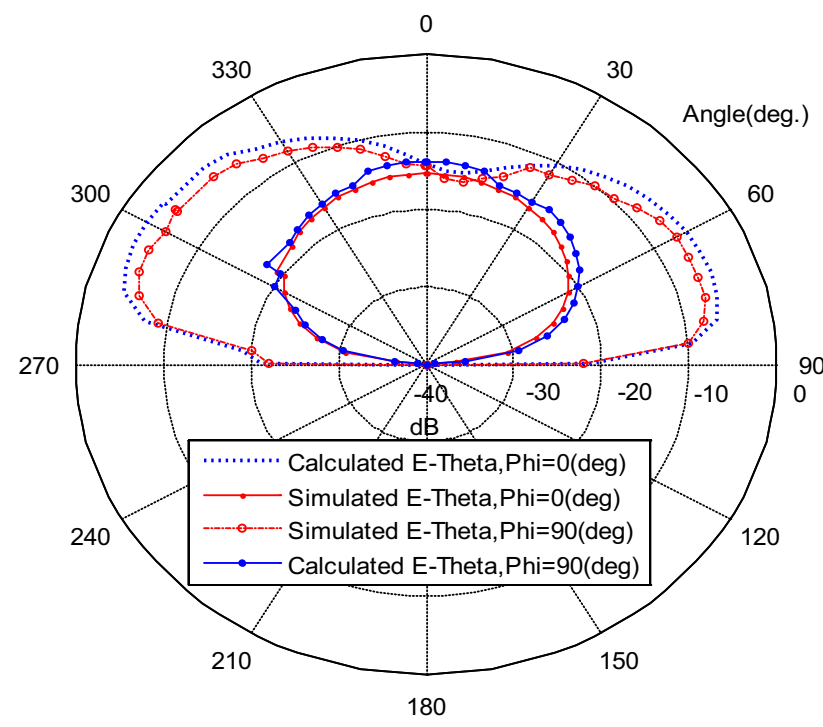

Fig. 12 Radiation pattern of proposed antenna for E- and H-plane at $2.37 \mathrm{GHz}$ resonation

\section{Conclusion}

The designed radiating structure has given efficient performance at the desired frequency. It is found that proposed antenna can be used for detecting cancer cells, swelling and tumor on the human body. Antenna parametric analysis has been performed and it was observed that designed antenna characteristic depends on the notches etched over the radiating surface. Further, results comparison has been done for simulated antenna design on IE3D with circuit theory concept results simulated on MatLab. The reflection coefficient result is approximately matches with simulated, theoretical and reported findings. The designed radiating structure can be used for wireless applications for WBAN and WMAN.

\section{Compliance with ethical standards}

Conflict of interest The authors declare that there is no conflict of interests regarding the publication of this paper.

\section{References}

1. Tak J, Kwon K, Choi J (2013) Design of a circular-ring patch onbody antenna with shorting vias for WBAN application. In: 2013 Asia-Pacific microwave conference proceedings (APMC), pp 557-559

2. Kim S, Kwon K, Choi J (2013) A compact circularly-polarized antenna with enhanced bandwidth for WBAN applications. Microw Opt Technol Lett 55:1738-1741

3. Chandran AR, Morris S, Timmons N, Morrison J (2015) Antenna with switchable propagating modes for WBAN applications. In: 2015 loughborough antennas and propagation conference (LAPC), pp 1-3
4. Lee W, Choi J (2015) A dual-band printed antenna with metal back-cover for WBAN applications. In: 2015 IEEE international symposium on antennas and propagation and USNC/URSI national radio science meeting, pp 936-937

5. Boutejdar A, Ibrahim AA, Burte EP (2015) A compact multiple band-notched planer antenna with enhanced bandwidth using parasitic strip lumped capacitors and DGS-technique. TELKOMNIKA Indones J Electr Eng 13(2):203-208

6. Boutejdar A, Halim BI, Hani SE, Bellarbi L, Afyf A (2018) Design of multiband microstrip antenna using stepped cut method for WLAN/WiMAX and C/Ku-band applications. World Acad Sci Eng Technol Int J Electron Commun Eng. https://doi.org/10.5281/ zenodo. 1317148

7. Boutejdar A, Ibrahim AA, Burte EP (2015) Novel microstrip antenna aims at UWB applications. Microw RF 54:62-66

8. Boutejdar A, Omar A, Burte E (2014) High-performance wide stop band low-pass filter using a vertically coupled DGS-DMS-resonators and interdigital capacitor. Microw Opt Technol Lett 56:87-91

9. Boutejdar A (2014) Design of broad-stop band low pass filter using a novel quasi-Yagi-DGS-resonators and metal box-technique. Microw Opt Technol Lett 56:523-528

10. Shafique K, Khawaja BA, Tarar MA, Khan BM, Raza A (2016) A wearable ultra-wideband antenna for wireless body area networks. Microw Opt Technol Lett 55:1710-1715

11. Kang D-G, Tak J, Choi J (2016) Low-profile dipole antenna with parasitic elements for WBAN applications. Microw Opt Technol Lett 58:1093-1097

12. Bansal R, Bhatia J, Batth A, Saini HS, Kumar N (2016) A novel lower ultra wideband (UWB) compact planar inverted-F antenna for WBAN applications. In: 2016 5th international conference on reliability, Info com technologies and optimization (trends and future directions) (ICRITO), pp 464-467

13. Gao G-P, Hu B, Tian X-L, Zhao Q-L, Zhang B-T (2017) Experimental study of a wearable aperture-coupled patch antenna for wireless body area network. Microw Opt Technol Lett 59:761-766

14. Vallappil AK, Khawaja BA, Khan I, Mustaqim M (2017) Dual-band Minkowski-Sierpinski fractal antenna for next generation satellite communications and wireless body area networks. Microw Opt Technol Lett 60:171-178

15. Türkmen $M$, Yalduz $H$ (2017) Design and analysis of quad-band grid array microstrip antenna at UWB and ISM channel frequencies for WBAN operations. In: 2017 10th international conference on electrical and electronics engineering (ELECO), pp 991-994

16. Saetiaw C (2017) Design of textile capsuleshaped patch antenna for WBAN applications. In: 2017 9th international conference on information technology and electrical engineering (ICITEE), pp 1-4

17. Masood R, Person C, Sauleau R (2017) A dual-mode, dual-port pattern diversity antenna for $2.45-\mathrm{GHz}$ WBAN. IEEE Antennas Wirel Propag Lett 16:1064-1067

18. Singh A, Kamakshi MA, Ansari JA (2017) Analysis of microstip line fed patch antenna for wireless communications. Open Eng J 7:279-286

19. Singh A, Ansari JA, Kamakshi K, Mishra A, Aneesh M (2014) Compact notch loaded half disk patch antenna for dualband operation. Ann Telecommun 69:475-483

20. Singh A, Ansari JA, Kamakshi M, Aneesh SS Sayeed (2014) L-strip proximity fed gap coupled compact semi-circular disk patch antenna. AEJ Alex Eng J 53(1):61-67

21. Koo T-W, Hong Y-J, Park G-K, Shin K, Yook J-G (2015) Extremely low profile antenna for attachable bio-sensors. IEEE Trans Antennas Propag 63(4):1537-1545

Publisher's Note Springer Nature remains neutral with regard to jurisdictional claims in published maps and institutional affiliations. 